\title{
3D stereophotogrammetric analysis of lip and nasal symmetry after primary cheiloseptoplasty in complete unilateral cleft lip repair*
}

\author{
Bram van Loon ${ }^{\#, 1,4}$, Srinivas G. Reddy ${ }^{\#, 2}$, Niels van Heerbeek ${ }^{3,4}$, Koen J.A.O. \\ Ingels $^{3,4}$, Thomas J.J. Maal ${ }^{1,4}$, Wilfred A. Borstlap ${ }^{1,4}$, Rajgopal R. Reddy ${ }^{2}$, \\ Anne-Marie Kuijpers-Jagtman ${ }^{5}$, Stefaan J. Bergé ${ }^{1,4}$ \\ 1 Department of Oral and Maxillofacial Surgery, Radboud University Nijmegen Medical Centre, Nijmegen, \\ The Netherlands \\ 2 GSR Institute of Craniofacial Surgery, Hyderabad, India \\ 3 Department of Otorhinolaryngology, Radboud University Nijmegen Medical Centre, Nijmegen, \\ The Netherlands \\ 4 Facial Imaging Research Group, Nijmegen, Bruges \\ 5 Department of Orthodontics and Oral Biology, Radboud University Nijmegen Medical Centre, Nijmegen, \\ The Netherlands
}

All authors are united in the Centre for Facial Plastic Surgery, Radboud University

Nijmegen Medical Centre, Nijmegen, The Netherlands

SUMMARY

Background: The aim of this study was to evaluate symmetry of the lip and nose in patients with CUCLP after primary cheiloseptoplasty (Afroze technique), in comparison to noncleft controls.

Methodology: In this prospective study, forty-four patients with operated non-syndromic CUCLP were included. The control group consisted of 44 volunteers without cleft defects of approximately the same age and sex. Primary septoplasty was performed in conjunction with the cleft lip (CL) repair using the Afroze incision. 3D facial images were acquired using 3D stereophotogrammetry. After a 3D cephalometric analysis of the lip and nose was performed in both groups, linear and volumetric data were acquired. Lip and nose symmetry were calculated and compared using Student's t-tests as well as the Chi square test.

Results: For all measurements, the control group was up to $36 \%$ closer to perfect symmetry compared to the CUCLP group after primary surgery. This difference was statistically significant.

Conclusions: After primary cheiloseptoplasty according to the Afroze technique in patients with CUCLP, asymmetry in the nose and lip area still exists as compared to non-cleft controls. Although non-cleft individuals also show some degree of asymmetry, the results of this study stress the difficulty in obtaining near normal symmetrical relations.

Key words: cleft palate, three-dimensional imaging, maxillofacial surgery, nose, rhinoplasty, $3 D$ sterophotogrammetry, volume.

\section{INTRODUCTION}

The ultimate goal for repair of the complete unilateral cleft lip, alveolus and palate (CUCLP) deformity is to create normal oronasal form and function. This aim has resulted in a plethora of techniques and innovations to optimize the esthetic and functional results. However, the management of CUCLP deformities, especially that of the nose, remains a challenge.
Various studies ${ }^{(1-8)}$ have been undertaken to evaluate the results of different operative procedures to correct the CUCLP nose deformity. However, quantification of rhinoplastic procedures remains difficult. Besides direct anthropometric measurements ${ }^{(9)}$, studies comparing pre- and postoperative nose and lip changes in patients with clefts are limited to two dimension- 
al (2D) photographs and radiographs ${ }^{(10,11)}$. Nevertheless, the human face is a three dimensional (3D) structure and various 3D imaging techniques have been developed to overcome the shortcomings of conventional $2 \mathrm{D}$ imaging. These include $3 \mathrm{D}$ cephalometry ${ }^{(12)}$, Moiré topography ${ }^{(13)}$, 3D laser scanning ${ }^{(14)}$, 3D optoelectronic digitizers ${ }^{(15)}$ and 3D stereophotogrammetry ${ }^{(16-18)}$. The latter method has gained popularity over the last years as digital 3D data sets of the face can be acquired rapidly, non-invasively, and simultaneously be stored digitally for future analysis ${ }^{(19)}$. Recent studies have shown 3D facial measurements acquired with a 3D stereophotogrammetrical camera setup to be valid, reproducible ${ }^{(19,20)}$ and clinically useful ${ }^{(21-23)}$.

The Afroze technique, described by Reddy et al., (24) is performed in conjunction with a primary functional septoplasty to achieve close to normal symmetry of the nose. However, data of the achieved symmetry and the comparison to healthy volunteers are still lacking. To the best knowledge of the authors, so far just one study evaluated facial symmetry in infants, including symmetry of the nose, after Millard lip and McComb nose repair ${ }^{(25)}$. Therefore, the aim of this study was to assess the outcome of lip and nasal symmetry with the help of 3D stereophotogrammetry in a group of patients with CUCLP after complete cleft lip correction in combination with a primary septoplasty using the Afroze incision (24) and to compare these data with a group of healthy control subjects.

\section{MATERIALS AND METHODS}

Subjects

This prospective study was performed at a high volume cleft center (the GSR Institute of Craniofacial Surgery, Hyderabad, India). Forty-four one-year postoperative patients (18 female, 26 male; mean age 3.1 years, range 12 to 96 months) with non-syndromic CUCLP defects were included in this study, of which 29 had a left sided cleft and 15 a right sided cleft. The control group consisted of 44 healthy coeval volunteers (19 female, 25 male; mean age 3.6 years, range 12 to 72 months) taken randomly from a larger prospective study of individuals of the same population without cleft defects.

\section{Surgery}

Cleft lip correction was performed using the Afroze technique (24). Primary septoplasty was carried out simultaneously with the cleft lip repair. The septoplasty procedure involved muscle dissection after which the perichondrium on both sides of the septum was reflected. The septum was then lifted off the nasal spine and repositioned in its anatomical centre with the nasalis muscle from both sides approximated to form a sling around the septum. In this new position the septum has no bony support and is not associated with the nasal spine immediately postoperatively, but does get bony support as the palatal and alveolar shelves move closer together late postoperatively.

\section{$3 D$ stereophotogrammetry}

A 3D stereophotogrammetrical camera setup with integrated software program modular system V 1.0 (3dMDface ${ }^{\text {TM }}$ System, 3dMD LLC, Atlanta, GA, USA) was used to capture 3D pho- tographs of the face. The 3D photographs were generated from six 2D photographs taken simultaneously (four grey-scale photographs and two full color photographs). A polygon light pattern was projected onto the four grey-scale photographs. Based on this pattern and its deformed image, a 3D photograph was reconstructed. With this system it was possible to capture 180 degrees of the subjects face, which concurred with an ear-toear 3D photograph. 3D photographs of the control group and for the CUCLP group were acquired one year postoperative. Before 3D documentation, parental consent was obtained.

To isolate the region of interest on the 3D photographs, the neck and parts of the hair were trimmed using 3dMDpatient V3.0.1 software ${ }^{(26)}$. The 3D photograph was imported into Maxilim $^{\circledR}$ version 2.2.2.1 (Medicim NV, Mechelen, Belgium). To acquire linear measurements a modified 3D cephalometric analysis (27) was performed resulting in 3D photographs in a Cartesian coordinate system. The linear and volumetric measurements of the nose and lip (nostril sagittal length, nostril transversal length, vertical philtrum length, horizontal philtrum length and volume) are depicted in Table 1 and Figure 1. For the volumetric measurements of the nose the region of interest was lined by various planes based on the cephalometric analysis that was performed for the linear measurements. These planes defined the area of interest of the volume of the nose. Finally, the nose was divided into a left and a right half based on the median plane and a virtual volume could be computed.

\section{Statistical analysis}

To calculate the error of the method, 25 random 3D photographs were measured twice by two independent observers (TM and BvL). Correlation between both observers and within observers was evaluated using Pearson correlation. Furthermore the intra- and interobserver reliability was tested using Student's t-test with a p-value of $<0.05$ indicating a statistically significant difference. This was done for each variable separately. The volumetric measurements that were used in this study have been validated previously for the same observers ${ }^{(23)}$.

For two sided measurements, the asymmetry can be expressed as the percentual difference between the two sides. The asymmetry percentage was calculated for each patient and control and these results were then divided into $\leq 0.5 \%,>0.5$ and $\leq$ $5 \%,>5$ and $\leq 10 \%,>10$ and $\leq 15 \%$, and $>15 \%$ deviation from perfect symmetry. The mean and standard deviation for all measurements were calculated and the Student's t-test and Chi square test (Fisher's exact test) were performed. The statistical data analysis was performed with the SPSS software program, version 16.0 (SPSS Inc, Chicago, IL, USA).

\section{RESULTS}

Table 2 shows the intra- and interobserver analysis. The mean difference, $95 \%$ confidence interval, Pearson correlation coefficient, measurement error and p-value for the intra- and interobserver reliability showed no statistical significant differences 
$(\mathrm{p}<0.05)$ between and within the observers.

For all five measurements (nostril sagittal length, nostril transversal length, vertical philtrum length, horizontal philtrum length and volume) the Student's t-test showed a statistical significant difference for the asymmetry score (Table 3) between the two groups. The control group was found to be up to $36 \%$ closer to perfect symmetry compared to the operated CUCLP group.
In Figure 2 and Table 4 the distribution of the degree of deviation from perfect symmetry is given. The Chi square for the nostril sagittal length $(\mathrm{p}<0.001)$, nostril transverse length ( $p<0.001)$, vertical philtrum length $(p<0.001)$, horizontal philtrum length $(\mathrm{p}<0.001)$ and volume measurement $(\mathrm{p}<$ 0.001 ) indicated a statistically significant different distribution between the control and cleft group.
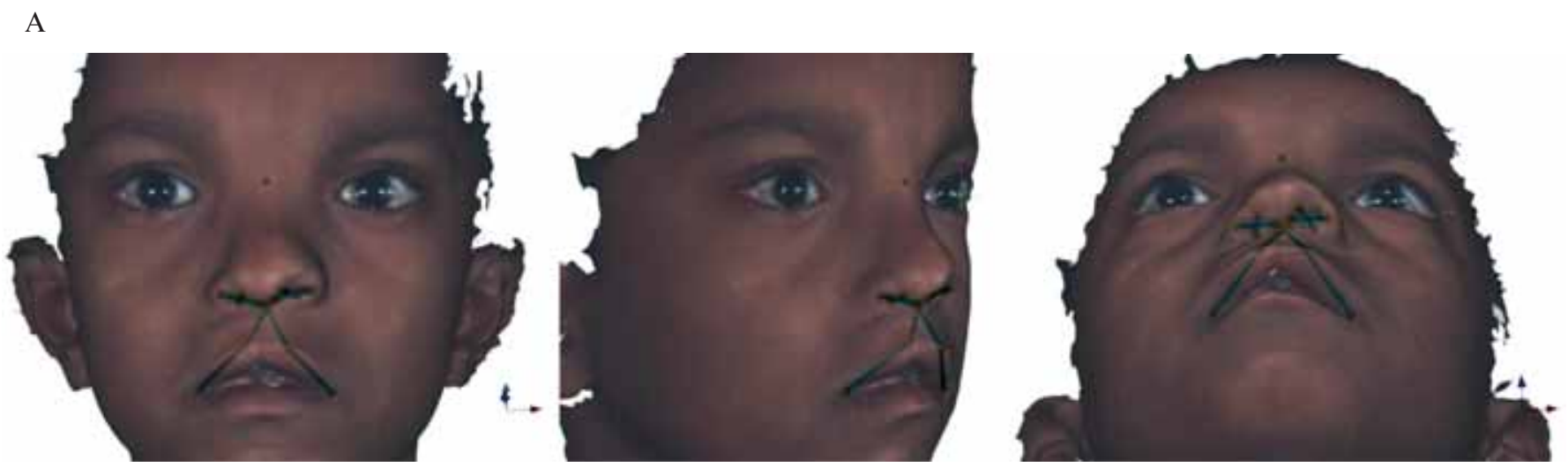

B
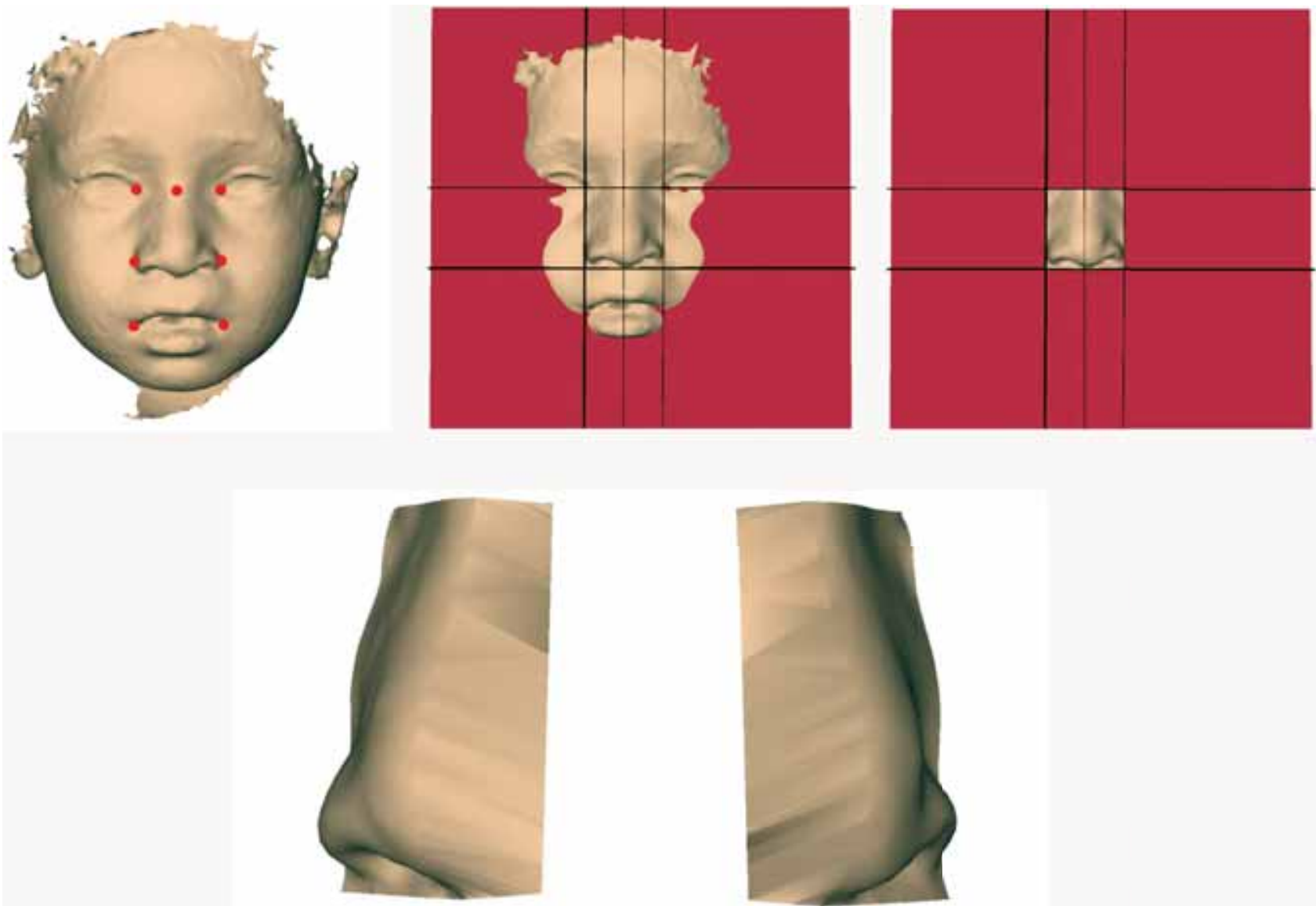

Figure 1. Linear and volumetric volumes used in this study. (A) Linear measurements used in this study as part of the cephalometric analysis. (B) The creation of the volumes for symmetry measurements. First the cephalometric analysis is performed after which the nose is lined by various planes. These planes are then used to cut the 3D photo and the two halves of the nose can be measured. 
A

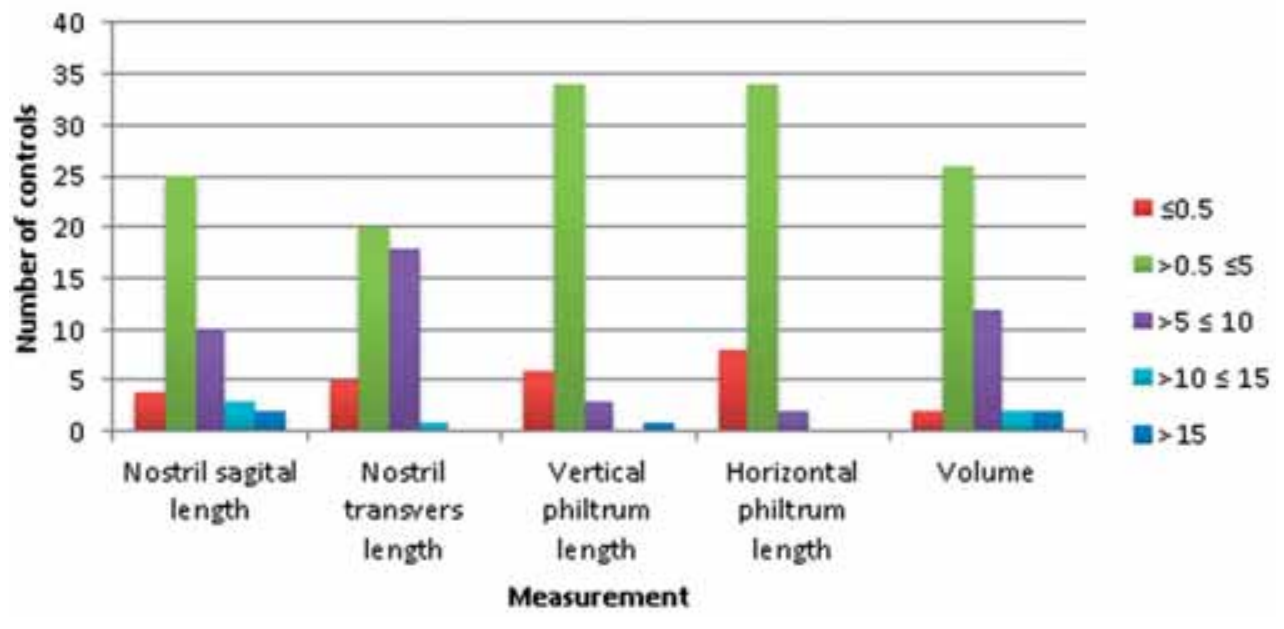

B

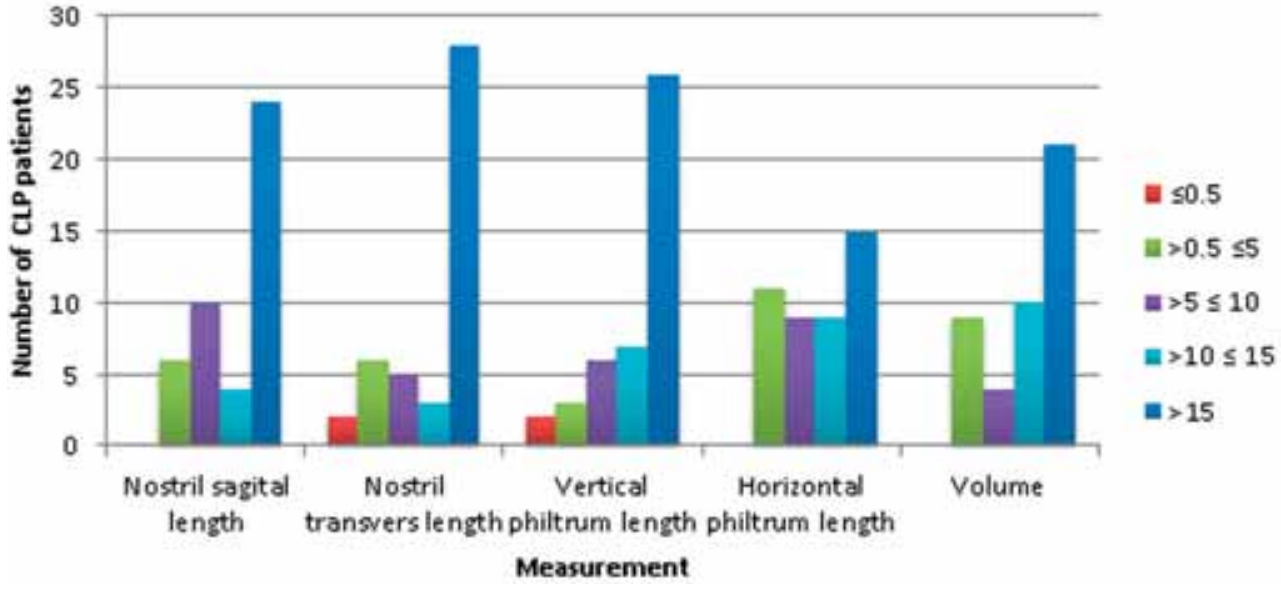

Figure 2. graphs showing the distribution of the deviation from perfect symmetry for both the control (A) and cleft (B) group for every measurement.

\section{DISCUSSION}

Using 3D stereophotogrammetry it was possible to assess the outcome of cleft lip surgery in combination with primary septoplasty using the Afroze incision for symmetry of lip and nose. Comparison of the CUCLP and control group revealed, even after corrective surgery, a significant difference concerning symmetry for both lip and nose measurements.

The first portfolio of stereoscopic photographs was created in the 1850 's ${ }^{(28)}$. From that point on, stereography evolved to modern $3 \mathrm{D}$ digital photographic systems. With the advent of digital technology, the applicability of 3D photographs in daily practice has become reality. The accuracy of various $3 \mathrm{D}$ imaging systems in recording facial morphologic features has been validated for various $3 \mathrm{D}$ modalities including the $3 \mathrm{dMD}$ system used in this study ${ }^{(4,7,19,20,29-33)}$. The results of these studies indicated the $3 \mathrm{dMD}$ system to be accurate and precise for facial purposes. Nevertheless several drawbacks of using 3D photographs can be identified for this study. Firstly, an error might occur when the $3 \mathrm{D}$ photographs are reconstructed. The 3D hard- and software has its limitations, especially in the reconstruction of for example the nostrils, because of the complex anatomy and the inability of the cameras to capture dark holes perfectly. As a consequence, the nostrils are a region of error and therefore identification of landmarks in this region can be difficult. A way to minimize this problem would be to use a Cone Beam CT (CBCT) 3D reconstruction of the nose. However, because of the radiation dose and long acquisition time, CBCT is not applicable for longitudinal follow up whereas 3D photographs are harmless.

Secondly, an error may occur during placement of the landmarks used in this study. In this study landmarks were used to compute linear measurements and to dictate the planes lining the right and left half of the nose for volumetric measurements. Earlier studies showed that identification of landmarks on 3D photographs can be difficult and lead to a small 
Table 1. Names and definitions of the linear measurements used.

\begin{tabular}{ll}
\hline Name & Description \\
\hline Nostril Sagittal left & Distance between landmarks Anterior Nostril (left) and Posterior Nostril (left) \\
Nostril Sagittal right & Distance between landmarks Anterior Nostril (right) and Posterior Nostril (right) \\
Nostril transverse left & Distance between landmarks Medial Nostril (left) and Lateral Nostril (left) \\
Nostril transverse right & Distance between landmarks Medial Nostril (right) and Lateral Nostril (right) \\
Vertical philtrum length left & Distance between landmarks Subnasale and Philtrum (left) \\
Vertical philtrum length right & Distance between landmarks Subnasale and Philtrum (right) \\
Horizontal philtrum length left & Distance between landmarks Philtrum (left) and Cheilion (left) \\
Horizontal philtrum length right & Distance between landmarks Philtrum (right) and Cheilion (right) \\
\hline
\end{tabular}

Table 2 Intra- and interobserver analysis. The mean difference between the measurements with a 95\% confidence interval and p-value, $\underline{\text { Pearson reliability coefficient and measurement error are given. No statistical significant differences were found. }}$

\begin{tabular}{|c|c|c|c|c|c|c|c|}
\hline & & \multirow{2}{*}{$\begin{array}{l}\text { Mean } \\
\text { difference } \\
(\mathrm{mm})\end{array}$} & \multicolumn{2}{|c|}{$95 \%$ CI of the Difference } & \multirow{2}{*}{$\begin{array}{l}\text { Significance } \\
\text { (2-tailed) }\end{array}$} & \multirow{2}{*}{$\begin{array}{l}\text { Reliability } \\
\text { coefficient }\end{array}$} & \multirow{2}{*}{$\begin{array}{l}\text { Measuremen } \\
\text { error }\end{array}$} \\
\hline & & & Lower & Upper & & & \\
\hline \multirow{4}{*}{ Nostril sagittal left } & intra 1 & 0.08 & -0.12 & 0.29 & 0.40 & 0.98 & 0.35 \\
\hline & intra 2 & 0.05 & -0.16 & 0.26 & 0.54 & 0.98 & 0.36 \\
\hline & inter 1 & 0.04 & -0.24 & 0.32 & 0.79 & 0.95 & 0.48 \\
\hline & inter 2 & 0.12 & -0.34 & 0.59 & 0.71 & 0.95 & 0.80 \\
\hline \multirow{4}{*}{ Nostril sagittal right } & Intra 1 & 0.08 & -0.22 & 0.39 & 0.58 & 0.91 & 0.53 \\
\hline & intra 2 & -0.07 & -0.24 & 0.1 & 0.38 & 0.97 & 0.29 \\
\hline & inter 1 & -0.02 & -0.26 & 0.23 & 0.89 & 0.95 & 0.42 \\
\hline & inter 2 & -0.13 & -0.54 & 0.29 & 0.28 & 0.94 & 0.71 \\
\hline \multirow{4}{*}{ Nostril transverse left } & intra 1 & 0.16 & -0.23 & 0.56 & 0.4 & 0.81 & 0.67 \\
\hline & intra 2 & 0.01 & -0.28 & 0.29 & 0.79 & 0.87 & 0.48 \\
\hline & inter 1 & -0.17 & -0.37 & 0.03 & 0.1 & 0.95 & 0.35 \\
\hline & inter 2 & -0.04 & -0.33 & 0.25 & 0.81 & 0.91 & 0.49 \\
\hline \multirow{4}{*}{ Nostril transverse right } & intra 1 & -0.16 & -0.73 & 0.41 & 0.57 & 0.7 & 0.97 \\
\hline & intra 2 & 0.01 & -0.18 & 0.19 & 0.59 & 0.97 & 0.31 \\
\hline & inter 1 & -0.12 & -0.35 & 0.1 & 0.27 & 0.96 & 0.39 \\
\hline & inter 2 & 0.22 & -0.3 & 0.75 & 0.17 & 0.77 & 0.9 \\
\hline \multirow{4}{*}{$\begin{array}{l}\text { Vertical philtrum length } \\
\text { left }\end{array}$} & intra 1 & 0.1 & -0.44 & 0.64 & 0.7 & 0.72 & 0.92 \\
\hline & intra 2 & -0.07 & -0.41 & 0.27 & 0.52 & 0.89 & 0.58 \\
\hline & inter 1 & 0.2 & -0.09 & 0.49 & 0.17 & 0.93 & 0.5 \\
\hline & inter 2 & -0.38 & -0.87 & 0.11 & 0.09 & 0.77 & 0.83 \\
\hline \multirow{4}{*}{$\begin{array}{l}\text { Vertical philtrum length } \\
\text { right }\end{array}$} & intra 1 & 0.33 & -0.37 & 1.03 & 0.34 & 0.73 & 1.2 \\
\hline & intra 2 & -0.01 & -0.37 & 0.36 & 0.95 & 0.93 & 0.63 \\
\hline & inter 1 & -0.02 & -0.33 & 0.29 & 0.9 & 0.95 & 0.54 \\
\hline & inter 2 & -0.38 & -1.12 & 0.36 & 0.27 & 0.82 & 1.27 \\
\hline \multirow{4}{*}{$\begin{array}{l}\text { Horizontal philtrum } \\
\text { length left }\end{array}$} & intra 1 & 0.01 & -0.5 & 0.52 & 0.96 & 0.9 & 0.88 \\
\hline & intra 2 & -0.22 & -0.65 & 0.21 & 0.53 & 0.95 & 0.74 \\
\hline & inter 1 & 0.06 & -0.29 & 0.42 & 0.48 & 0.93 & 0.61 \\
\hline & inter 2 & -0.24 & -0.82 & 0.33 & 0.35 & 0.86 & 0.99 \\
\hline \multirow{4}{*}{$\begin{array}{l}\text { Horizontal philtrum } \\
\text { length right }\end{array}$} & intra 1 & 0.40 & -0.12 & 0.91 & 0.12 & 0.88 & 0.88 \\
\hline & intra 2 & -0.05 & -0.35 & 0.24 & 0.9 & 0.96 & 0.5 \\
\hline & inter 1 & -0.33 & -0.78 & 0.12 & 0.25 & 0.89 & 0.77 \\
\hline & inter 2 & -0.14 & -0.8 & 0.51 & 0.74 & 0.82 & 1.13 \\
\hline
\end{tabular}


Table 3. Group statistics with mean and standard deviation of the asymmetry as a percentage from perfect symmetry for the control and CUCLP group. Mean difference (percentage), standard deviation, standard error, 95\% confidence interval and p-value (Student's t-test) between the control group and the CUCLP group are given for the deviation from perfect symmetry. All measurements show statistical significant difference between the CUCLP group and the control group.

\begin{tabular}{|c|c|c|c|c|c|c|c|}
\hline & \multirow{2}{*}{ Group } & \multirow{2}{*}{ Mean (\%) and SD } & \multirow{2}{*}{$\begin{array}{l}\text { Mean Diff } \\
(\%)\end{array}$} & \multirow{2}{*}{$\begin{array}{l}\text { Std Error } \\
\text { Diff }\end{array}$} & \multicolumn{2}{|c|}{$\begin{array}{l}95 \% \text { Confidence interval of } \\
\text { the Difference }\end{array}$} & \multirow[t]{2}{*}{$\underset{\text { (2-tailed) }}{\text { Sign }}$} \\
\hline & & & & & Lower & Upper & \\
\hline \multirow{2}{*}{ Nostril sagittal length } & Control & $4.88 \pm 4.16$ & \multirow{2}{*}{-36.45} & \multirow{2}{*}{11.22} & \multirow{2}{*}{-58.76} & \multirow{2}{*}{-14.14} & \multirow{2}{*}{0.002} \\
\hline & CUCLP & $41.34 \pm 74.34$ & & & & & \\
\hline \multirow{2}{*}{$\begin{array}{l}\text { Nostril transversal } \\
\text { length }\end{array}$} & Control & $4.46 \pm 3.02$ & \multirow{2}{*}{-23.36} & \multirow{2}{*}{3.59} & \multirow{2}{*}{-30.51} & \multirow{2}{*}{-16.23} & \multirow{2}{*}{$<0.001$} \\
\hline & CUCLP & $27.83 \pm 23.62$ & & & & & \\
\hline \multirow{2}{*}{ Vertical philtrum length } & Control & $2.94 \pm 2.61$ & \multirow{2}{*}{-20.96} & \multirow{2}{*}{2.79} & \multirow{2}{*}{-26.51} & \multirow{2}{*}{-15.39} & \multirow{2}{*}{$<0.001$} \\
\hline & CUCLP & $23.89 \pm 18.36$ & & & & & \\
\hline \multirow{2}{*}{$\begin{array}{l}\text { Horizontal philtrum } \\
\text { length }\end{array}$} & Control & $1.85 \pm 1.54$ & \multirow{2}{*}{-12.82} & \multirow{2}{*}{2.52} & \multirow{2}{*}{-17.83} & \multirow{2}{*}{-7.82} & \multirow{2}{*}{$<0.001$} \\
\hline & CUCLP & $14.68 \pm 16.63$ & & & & & \\
\hline \multirow{2}{*}{ Volume } & Control & $4.76 \pm 4.24$ & \multirow{2}{*}{-12.77} & \multirow{2}{*}{2.11} & \multirow{2}{*}{-16.98} & \multirow{2}{*}{-8.57} & \multirow{2}{*}{$<0.001$} \\
\hline & CUCLP & $17.54 \pm 13.37$ & & & & & \\
\hline
\end{tabular}

Table 4. Asymmetry distribution for the control group and CUCLP group. The patients and controls are distributed over 5 categories ranging from $0 \%$ to $>15 \%$ deviation from perfect symmetry.

\begin{tabular}{|c|c|c|c|c|c|c|c|c|c|c|}
\hline \multirow[b]{2}{*}{ Deviation from 0} & \multicolumn{4}{|c|}{ Control group $(\mathrm{N}=44)$} & \multicolumn{6}{|c|}{ CUCLP (N=44) } \\
\hline & $\leq 0.5$ & $\begin{array}{l}>0.5 \text { and } \\
\leq 5\end{array}$ & $\begin{array}{l}>5 \text { and } \\
\leq 10\end{array}$ & $\begin{array}{c}>10 \text { and } \\
\leq 15\end{array}$ & $>15$ & $\leq 0.5$ & $\begin{array}{l}>0.5 \text { and } \\
\leq 5\end{array}$ & $\begin{array}{l}>5 \text { and } \\
\leq 10\end{array}$ & $\begin{array}{c}>10 \text { and } \\
\leq 15\end{array}$ & $>15$ \\
\hline $\begin{array}{l}\text { Nostril Sagittal } \\
\text { length }\end{array}$ & 4 & 25 & 10 & 3 & 2 & 0 & 6 & 10 & 4 & 24 \\
\hline $\begin{array}{l}\text { Nostril Trans- } \\
\text { verse length }\end{array}$ & 5 & 20 & 18 & 1 & 0 & 2 & 6 & 5 & 3 & 28 \\
\hline $\begin{array}{l}\text { Vertical Philtrum } \\
\text { length }\end{array}$ & 6 & 34 & 3 & 0 & 1 & 2 & 3 & 6 & 7 & 26 \\
\hline $\begin{array}{l}\text { Horizontal } \\
\text { Philtrum length }\end{array}$ & 8 & 34 & 2 & 0 & 0 & 0 & 11 & 9 & 9 & 15 \\
\hline Volume & 2 & 26 & 12 & 2 & 2 & 0 & 9 & 4 & 10 & 21 \\
\hline
\end{tabular}

error $^{(20,29,31)}$. The analysis of the measurement error of the present study showed that the intra- and interobserver reliability were adequate.

Another drawback of this study is the lack of preoperative 3D patient data. Therefore the amount of improvement or impairment of the symmetry of the lip and nose as a direct effect of surgery cannot be measured. By comparing the result to a noncleft control group, however, we can estimate to which extend a close to normal symmetry was reached. In a previous study ${ }^{(23)}$, volumetric changes of the nose in patients with a CUCLP were documented before and after secondary rhinoplasty. Despite improvements, perfect symmetry could not be achieved.

Several studies used 3D techniques to evaluate the soft tissues of the face of patients with orofacial clefts in comparison to controls. Hood et al., ${ }^{(25)}$ used the C3D stereophotogrammetry system to assess facial symmetry in 20 patients with orofacial clefts, after Millard lip, McComb nose and palate repair, and compared the results with non-cleft age-matched controls. Preand postoperative facial asymmetry was evaluated by calculating distances between landmarks and their mirror images and expressing the result as an asymmetry score for each area of interest. The unilateral CLP group was more asymmetric than the unilateral CL group and these again were more asymmetric than the control group.

Bilwatsch et al., ${ }^{(34)}$ assessed the degree of facial symmetry in patients with CUCLP with an optical 3D sensor, which implied that textured information was not available. Twenty-two ten year-old patients with CUCLP who underwent the TennisonRandall technique without primary rhinoplasty and without 
further revision surgery, were included. After establishing a plane of symmetry, differences were determined between landmarks, surface areas and virtual volumes of various areas of interest. Statistically significant differences could be found between cleft and non-cleft sides. They concluded that complete nasal symmetry was difficult to achieve with TennisonRandall's lip repair without revision surgery.

The various linear and volumetric measurements in the present study indicated the symmetry of the patient group with CUCLP to differ significantly from the control group. For all measurements the control group was up to $36 \%$ (Table 3) closer to perfect symmetry compared to the postoperative CUCLP group. The nostrils seemed to be the area where most deviation existed. The volumetric measurements, which give an indication of symmetry for the whole nose, indicated the control group to be mostly symmetric with 75 percent of controls having a symmetry score within five percent deviation from perfect symmetry. For the group with CUCLP this was just 18 percent, which indicated a significant difference. This shows that the Afroze technique in combination with a functional repair of the nose is not able to achieve near normal symmetry. Whether other techniques are performing better remains to be investigated and asks for a randomized clinical trial design with direct comparison of different techniques and 3D analysis of the outcome.

\section{Conclusions}

After primary cheiloseptoplasty according to the Afroze technique in patients with CUCLP asymmetry in the nasal and lip area still exists as compared to non-cleft controls. Although non-cleft individuals also show some degree of asymmetry the results of this study stress the difficulty in obtaining near normal symmetrical relations.

\section{ACKNOWLEDGEMENTS}

Sources of funds for this study: This work was supported by a grant from the Dutch Technology Foundation (STW - nr. 10315).

\section{AUTHOR CONTRIBUTIONS}

The authors thank Ewald Bronkhorst, PhD, working at the Department of Preventive and Curative dentistry, Radboud University Nijmegen Medical Centre, for his help with the statistical analysis.

\section{CONFLICT OF INTEREST}

None declared

\section{REFERENCES}

1. Nolst Trenite GJ, Paping RH, Trenning AH. Rhinoplasty in the cleft lip patient. Cleft Palate Craniofac J. 1997; 34: 63-68.

2. Gryskiewicz JM, Rohrich RJ, Reagan BJ, Schwartz BM. The Use of AlloDerm for the Correction of Nasal Contour Deformities. Plast Reconstr Surg. 2001; 107: 571.

3. Anastassov GE, Joos U, Zöllner B. Evaluation of the results of delayed rhinoplasty in cleft lip and palate patients. Functional and aesthetic implications and factors that affect successful nasal repair. Br J Oral Maxillofac Surg. 1998; 36: 416-424.

4. Honrado CP, Lee S, Bloomquist DS, Larrabee WF, Jr. Quantitative assessment of nasal changes after maxillomandibular surgery using a 3-dimensional digital imaging system. Arch Facial Plast Surg. 2006; 8: 26-35.

5. Kane AA, Pilgram TK, Moshiri M, Marsh JL. Long-term outcome of cleft lip nasal reconstruction in childhood. Plast Reconstr Surg. 2000; 105: 1600-1608.

6. Lo LJ, Wong FH, Mardini S, Chen YR, Noordhoff MS Assessment of bilateral cleft lip nose deformity: a comparison of results as judged by cleft surgeons and laypersons. Plast Reconstr Surg. 2002; 110: 733-738; discussion 9-41.

7. Nagy K MM. Analysis of the cleft-lip nose in submental--vertical view, part 1 - Reliability of a new measurement instrument. J Craniomaxillofac Surg. 2007; 35: 265-277.

8. Sandor GK, Ylikontiola LP. Patient evaluation of outcomes of external rhinoplasty for unilateral cleft lip and palate. Int J Oral Maxillofac Surg. 2006; 35: 407-11.

9. Farkas LG. Anthropometry of the head and face: Raven Press 1994.

10. Quintero JC, Trosien A, Hatcher D, Kapila S. Craniofacial imaging in orthodontics: historical perspective, current status, and future developments. Angle Orthod. 1999; 69: 491-506.

11. Kim SK, Cha BH, Lee KC, Park JM. Primary correction of unilateral cleft lip nasal deformity in Asian patients: anthropometric evaluation. Plast Reconstr Surg. 2004; 114: 1373-1381.

12. Swennen GR, Schutyser FA, Barth EL, De Groeve P, De Mey A. A new method of 3-D cephalometry Part I: the anatomic Cartesian 3-D reference system. J Craniofac Surg. 2006; 17: 314-325.

13. Takasaki H. Moiré Topography. Appl Opt. 1970; 9: 1467-1472.

14. Blais F. Review of 20 years of range sensor development. J. Electron. Imaging. 2004; 13: 231-43.

15. Ferrario VF, Sforza C, Poggio CE, Schmitz JH. Threedimensional study of growth and development of the nose. Cleft Palate Craniofac J. 1997; 34: 309-317.

16. Honrado CP, Larrabee WF, Jr. Update in three-dimensional imaging in facial plastic surgery. Curr Opin Otolaryngol Head Neck Surg. 2004; 12: 327-331.

17. Kau CH, Richmond S, Incrapera A, English J, Xia JJ. Threedimensional surface acquisition systems for the study of facial morphology and their application to maxillofacial surgery. Int $\mathbf{J}$ Med Robot. 2007; 3: 97-110.

18. Ras F, Habets LL, van Ginkel FC, Prahl-Andersen B. Threedimensional evaluation of facial asymmetry in cleft lip and palate. Cleft Palate Craniofac J. 1994; 31: 116-121.

19. Aldridge K, Boyadjiev SA, Capone GT, DeLeon VB, Richtsmeier JT. Precision and error of three-dimensional phenotypic measures acquired from 3dMD photogrammetric images. Am J Med Genet. 2005; 138: 247-253.

20. Plooij JM, Swennen GR, Rangel FA, et al. Evaluation of reproducibility and reliability of 3D soft tissue analysis using 3D stereophotogrammetry. Int J Oral Maxillofac Surg. 2009; 38: 267-73.

21. van Heerbeek N, Ingels KJ, van Loon B, Plooij JM, Berge SJ. Three dimensional measurement of rhinoplasty results. Rhinology. 2009; 47: 121-125.

22. van Loon B, Maal TJ, Heerbeek N, Ingels KJ, Bergé SJ. A volumetric study to compare the percutaneous and endonasal osteotomy techniques in rhinoplasty using 3D stereophotogrammetry. Rhinology. 2011; 49: 121-126.

23. van Loon B, Maal TJ, Plooij JM, et al. 3D Stereophotogrammetric assessment of pre- and postoperative volumetric changes in the cleft lip and palate nose. Int J Oral Maxillofac Surg. 2010; 39: 534-540.

24. Reddy GS, Reddy RR, Pagaria N, Berge S. Afroze incision for functional cheiloseptoplasty. J Craniofac Surg. 2009; 20 Suppl 2: 1733-1736.

25. Hood CA, Bock M, Hosey MT, Bowman A, Ayoub AF. Facial asymmetry--3D assessment of infants with cleft lip \& palate. Int J Paediatr Dent. 2003; 13: 404-410.

26. Maal TJ, Plooij JM, Rangel FA, Mollemans W, Schutyser FA, Berge SJ. The accuracy of matching three-dimensional photographs with skin surfaces derived from cone-beam computed tom- 
ography. Int J Oral Maxillofac Surg. 2008; 37: 641-646.

27. Gwen R.J. Swennen FACS, Jarg-Erich Hausamen. ThreeDimensional Cephalometry: A Color Atlas and Manual Springer; 2005.

28. Wheatstone C. Note on a new portable reflecting stereoscope. J Franklin Inst. 1853; 56: 205-206.

29. Weinberg SM, Naidoo S, Govier DP, Martin RA, Kane AA, Marazita ML. Anthropometric precision and accuracy of digital three-dimensional photogrammetry: comparing the Genex and $3 \mathrm{dMD}$ imaging systems with one another and with direct anthropometry. J Craniofac Surg. 2006; 17: 477-483.

30. Weinberg SM, Scott NM, Neiswanger K, Brandon CA, Marazita ML. Digital three-dimensional photogrammetry: evaluation of anthropometric precision and accuracy using a Genex 3D camera system. Cleft Palate Craniofac J. 2004; 41: 507-518.

31. Ghoddousi H, Edler R, Haers P, Wertheim D, Greenhill D. Comparison of three methods of facial measurement. Int J Oral Maxillofac Surg. 2007; 36: 250-258.

32. White JE, Ayoub AF, Hosey MT, Bock M, Bowman A, Bowman $\mathrm{J}$, et al. Three-dimensional facial characteristics of Caucasian infants without cleft and correlation with body measurements. Cleft Palate Craniofac J. 2004; 41: 593-602.

33. Ayoub A, Garrahy A, Hood C, White J, Bock M, Siebert JP, et al. Validation of a vision-based, three-dimensional facial imaging system. Cleft Palate Craniofac J. 2003; 40: 523-529.

34. Bilwatsch S, Kramer M, Haeusler G, Schuster M, Wurm J, Vairaktaris E, et al. Nasolabial symmetry following TennisonRandall lip repair: a three-dimensional approach in 10 -yearold patients with unilateral clefts of lip, alveolus and palate. J Craniomaxillofac Surg. 2006; 34: 253-262.

S. Bergé

Department of Oral and Maxillofacial Surgery Radboud University Nijmegen Medical Centre P.O. Box 9101

6500 HB Nijmegen

Postal number 590

The Netherlands

Tel: +31-24-361 4550

Fax: +31-24-354 1165

E-mail: s.berge@mka.umcn.nl

\section{9th INTERNATIONAL COURSE IN ADVANCED SINUS SURGERY TECHNIQUES}

\section{Dissection course with fresh frozen cadaver heads}

Teacher of Honour: Prof. Manuel Bernal Sprekelsen

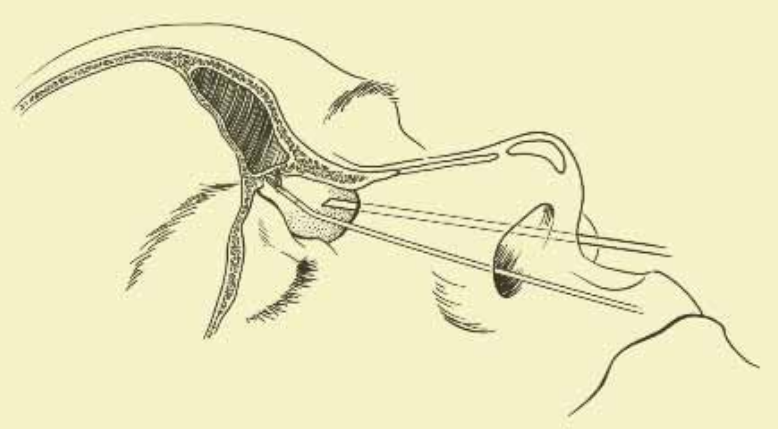

March 22-23 March, 2012

Department of Otorhinolaryngology Academic Medical Center of the University of Amsterdam The Netherlands

For further information contact Wytske J. Fokkens, $M D, P h D$ ENT dept. AMC Course Secretariat

Tel: 0031205668586 / Fax 0031205669573 Email:m.b.vanhuiden@amc.uva.nl 